\title{
Clinical Outcome of Patients With Severe Burns Presenting to the Emergency Department
}

\author{
Mehmet Tahir Gokdemir ${ }^{\mathrm{a}}$, Mustafa Aldemir ${ }^{\mathrm{b}}$, Ozgur Sogut ${ }^{\mathrm{a}, \mathrm{e}}$, Cahfer Guloglu, \\ Mustafa Burak Sayhan ${ }^{\mathrm{d}}$, Murat Orak ${ }^{\mathrm{c}}$, Mehmet Ustundag ${ }^{\mathrm{c}}$
}

\begin{abstract}
Background: Burns are a leading cause of morbidity and mortality worldwide. Although a local burn covering a limited surface area can heal readily, deep or extensive burns can result in systemic damage and even death. This study evaluated the clinical characteristics of the patients presenting with severe burns and investigated the factors influencing mortality.
\end{abstract}

Methods: The data for 1003 patients who presented with symptoms of severe burn to a tertiary care university hospital in Turkey between 2006 and 2007 were evaluated retrospectively.

Results: The overall patient mortality was $7.7 \%(\mathrm{n}=78)$. The effect of male gender and age on mortality was significant. The highest mortality rate was in the group aged $>40$ years. A burned area larger than $21 \%$ of the body surface conferred a high risk of mortality. A hospital stay for longer than 10 days, the presence of delirium at the time of presentation, hyperuricemia, the need for debriding, grafting, or fasciotomy, sepsis, hypovolemic shock, and a positive blood culture were significant predictors of mortality.

Conclusions: Severe burns have to be treated in a burn unit or burn

Manuscript accepted for publication January 13, 2012

${ }^{a}$ Department of Emergency Medicine, Harran University, Faculty of Medicine, Sanliurfa, Turkey

${ }^{b}$ Department of General Surgery, Dicle University, Faculty of Medicine, Diyarbakir, Turkey.

${ }^{\mathrm{c}}$ Department of Emergency Medicine, Dicle University, Faculty of Medicine, Diyarbakir, Turkey

${ }^{\mathrm{d}}$ Department of Emergency Medicine, Trakya University, Faculty of Medicine, Edirne, Turkey

${ }^{\mathrm{e}}$ Corresponding author: Ozgur Sogut. Email: drosogut@harran.edu.tr

doi: $10.4021 / \mathrm{jcs} 19 \mathrm{e}$ center. As the prevention of burns is important, it is important to identify the region-specific causes of burns and the risk factors that influence mortality.

Keywords: Severe burn; Outcome; Clinical characteristics; Risk factors; Mortality

\section{Introduction}

The incidence of burns varies across countries, populations, and time. Studies have focused on burns in elderly people and children, in a war environment, among non-combatant military personnel, in populations with low-socioeconomic status, and among alcohol and substance abusers, who experience burn injuries more frequently $[1,2]$. The severity of a burn depends on the degree of heat, duration of exposure, and thickness of the involved skin [2].

The treatment of burns requires a multidisciplinary approach, it varies depending on the psychological and social status of the patient and the function of each organ, and it is expensive [3]. The main components of treatment are surgical intervention (early excision/skin grafting), volume therapy, the treatment of sepsis and multi-organ failure, nutrition, and rehabilitation [2,3]. A burn center must be well equipped, and it also requires the collaboration of various specialists, including general surgeons, plastic and reconstructive surgeons, infectious disease specialists, anesthetists, dieticians, psychologists, pediatricians, physiotherapists, microbiologists, and epidemiologists. The quality of nursing is also of great importance for successful outcomes [4].

This study determined the factors that influence mortality in patients who presented to the emergency department with electric, flame, or scald burns.

\section{Methods}

\section{Study design and participants}

This is a retrospective chart review study for which we col- 
Table 1. Distribution of Living and Dead Patients by Age Group and Gender

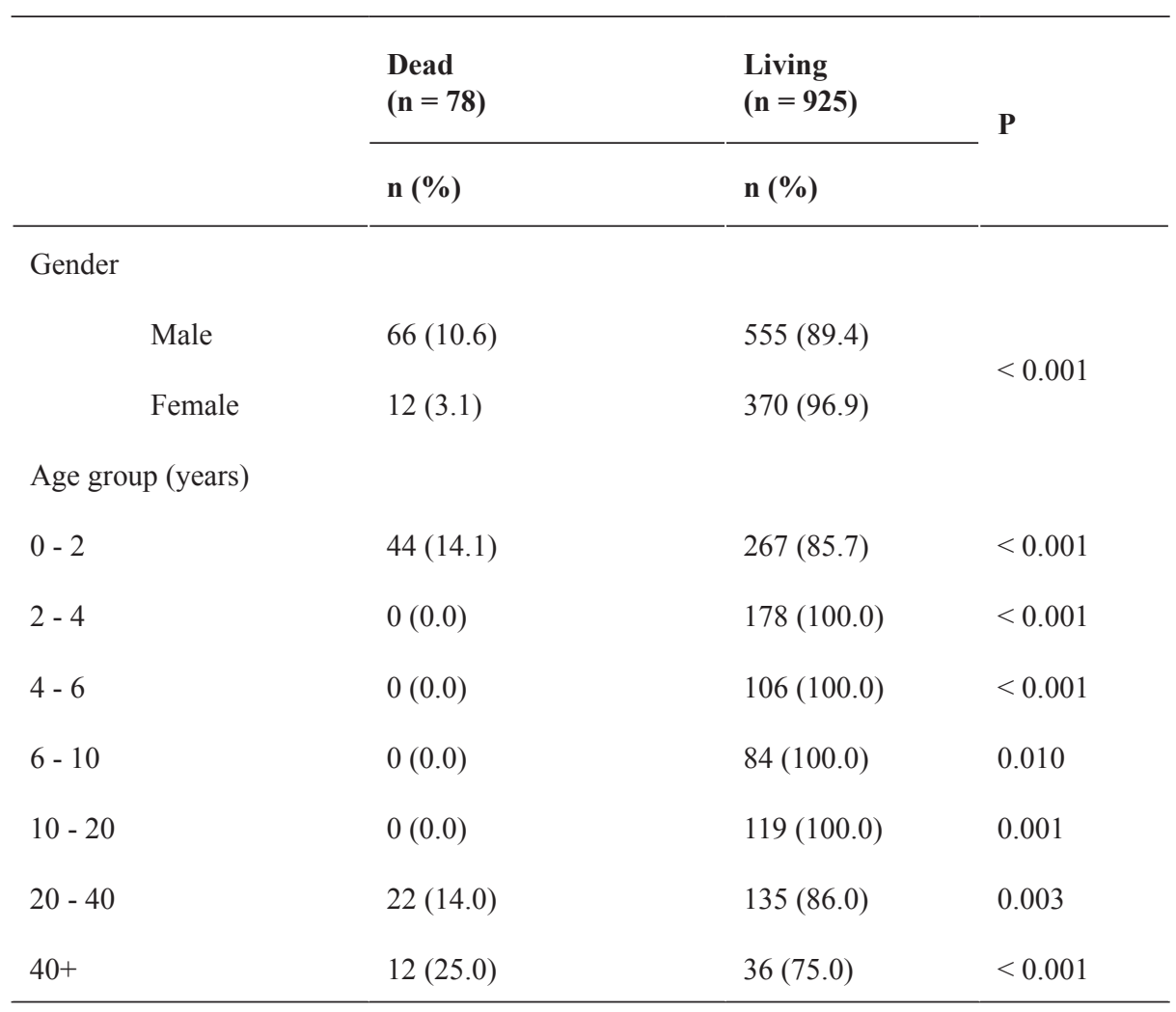

lected data from our hospital's digital patient database over a 24-month period (January 2006 through December 2007). The study enrolled 1443 patients who presented to the Emergency Department (ED) of a tertiary care university hospital, with symptoms of severe burn due to various causes (electric, flame, or scald burns). Of these, 236 were excluded from the study because they had first-degree burns or burns involving less than $5 \%$ of the body surface. An additional 204 were excluded due to incomplete data. The study protocol was approved by the Ethical Committee of Dicle University, Faculty of Medicine.

The initial treatment of all patients was done in our ED. After 24 to 48 hours of close monitoring and treatment in the special rooms for burn patients, those patients who had indications for hospitalization were transferred to the burn unit to continue their treatment. Patients without indications for hospitalization were either treated further in the ED or followed as outpatients depending on their status after 48 hours of close monitoring.

The indications for hospitalization were as follows: age $>50$ or $<10$ years with second- or third-degree burns involving $10 \%$ or more of the body surface; age $10-50$ years with second- and third-degree burns over $>15 \%$ of the body surface; second- and third-degree burns involving the perineum, genital region, extremities, face, and joint surfaces, which might cause esthetic or functional problems; third-degree burns involving more than $5 \%$ of the body surface; concurrent inhalation burns; circular and deep burns involving the extremities and chest wall; previous health problems; and concomitant trauma (extremity fractures, assault, head trauma, etc.).

\section{Data collection}

The parameters evaluated in the study that might influence the mortality rate were age, gender, cause of burn, type of burn (electric, flame, or scald), the season when the burn occurred, shock (arterial blood pressure $<90 / 60 \mathrm{mmHg}$ ) and tachypnea (respiratory rate $>20 / \mathrm{min}$ ) at the time of presentation, late presentation ( $>12$ hours), presence of delirium, hyperglycemia (glucose $>120 \mathrm{mg} / \mathrm{dL}$ ), hyperuricemia $(>50$ $\mathrm{mg} / \mathrm{dL})$, hypernatremia $\left(\mathrm{Na}^{+}>140 \mathrm{mmol} / \mathrm{L}\right)$, hyponatremia $\left(\mathrm{Na}^{+}<120 \mathrm{mmol} / \mathrm{L}\right)$, hyperkalemia $\left(\mathrm{K}^{+}>5 \mathrm{mmol} / \mathrm{L}\right)$, hypokalemia $\left(\mathrm{K}^{+}<3.5 \mathrm{mmol} / \mathrm{L}\right)$, hypoalbuminemia $(<3.5 \mathrm{~g} /$ $\mathrm{dL}$ ), elevated hepatic function tests (ALT $>55 \mathrm{U} / \mathrm{L}, \mathrm{AST}>$ $40 \mathrm{U} / \mathrm{L})$, increased CK-MB (>24 U/L), increased troponin $(>1 \mathrm{ng} / \mathrm{mL})$, increased CRP $(>8 \mathrm{mg} / \mathrm{L})$, leukocytosis $(>10$ $\mathrm{K} / \mu \mathrm{L}$ ), anemia (hematocrit $<30 \%$ ), metabolic acidosis $(\mathrm{pH}$ $<7.35$ ), increased lactate level ( $>8 \mathrm{mg} / \mathrm{dL}$ ), abnormal ECG (ST-T changes, dysrhythmias), location of the burn (head, body, extremity, and genital region), extent and depth of the burn, the unit the patient was admitted to (pediatric inten- 
Table 2. Clinical and Metabolic Characteristics of the Dead and Surviving Patient Groups at the Time of Presentation

\begin{tabular}{|c|c|c|c|}
\hline \multirow{2}{*}{ Characteristic } & $\begin{array}{c}\text { Dead } \\
(n=78)\end{array}$ & $\begin{array}{c}\text { Living } \\
(\mathrm{n}=925)\end{array}$ & \multirow{2}{*}{$\mathbf{P}$} \\
\hline & n $(\%)$ & n (\%) & \\
\hline Presence of shock & $19(24.4)$ & $169(18.3)$ & 0.090 \\
\hline Presence of tachypnea & $33(42.3)$ & $378(40.9)$ & 0.055 \\
\hline Late presentation & $20(25.6)$ & $221(23.9)$ & 0.053 \\
\hline Presence of delirium & $18(23.1)$ & $96(10.4)$ & 0.001 \\
\hline Hyperglycemia & $28(35.9)$ & $302(32.6)$ & 0.100 \\
\hline Hyperuremia & $7(9.0)$ & $23(2.5)$ & 0.006 \\
\hline Electrolyte imbalance & $3(3.8)$ & $14(1.5)$ & 0.080 \\
\hline Hypoalbuminemia & $59(75.6)$ & $634(68.5)$ & 0.061 \\
\hline Elevated hepatic enzymes & $20(25.6)$ & $228(24.6)$ & 0.059 \\
\hline Increased CK-MB & $17(21.8)$ & $222(24.0)$ & 0.060 \\
\hline Increased troponin & $8(10.3)$ & $77(8.3)$ & 0.057 \\
\hline Increased CRP & $61(78.2)$ & $734(79.4)$ & 0.066 \\
\hline Leukocytosis & $24(30.8)$ & $333(36.0)$ & 0.100 \\
\hline Anemia & $7(9.0)$ & $84(9.1)$ & 0.089 \\
\hline Presence of metabolic acidosis & $25(32.1)$ & $238(25.7)$ & 0.052 \\
\hline Elevated lactate level & $75(96.2)$ & $910(98.4)$ & 0.090 \\
\hline Abnormal ECG & $4(5.1)$ & $44(4.8)$ & 0.058 \\
\hline
\end{tabular}

sive care, burn unit, ambulatory, and others), complications (sepsis, shock, and positive blood and wound cultures), and surgical interventions.

\section{Data analyses}

Data analysis were conducted using SPSS v.15.0 software (SPSS, Inc., Chicago, IL, USA). Statistical analyses were done using the chi square test $\left(\chi^{2}\right)$ for categorical variables and Student's $t$-test for continuous variables. $\mathrm{P}<0.05$ was considered significant.

\section{Results}

Of the participants, $62 \%(\mathrm{n}=621)$ were male, and $38 \%(\mathrm{n}$ $=382$ ) were female. The overall mortality rate was $7.7 \%$ (n $=78)$. The mortality rate among males $(10.6 \%)$ was higher than that among females $(3.1 \%)$. The mortality rate was the highest $(25 \%)$ in the $40+$ year age group. The distribution of living and dead patients by age group and gender is shown in Table 1.

Of the 78 patients who died, $44(56.4 \%)$ were 0 - 2 years old, $22(28.2 \%)$ were 20 - 40 years old, and $12(15.4 \%)$ were $40+$ years old.

The leading cause of the burns was a home accident in $69.3 \%(n=695)$, followed by inattention in $10.6 \%(n=107)$ and occupational accidents in $4.5 \%(n=45)$. There was no significant difference between the dead and survivor groups in terms of the cause of the burn $(\mathrm{P}=0.080)$.

Burns were more common in winter $(33.2 \%, \mathrm{n}=333)$, than in spring $(30.1 \%)$, autumn $(22.2 \%)$, and summer $(14.6 \%)$. There was no significant difference between the patient groups in terms of seasonal distribution $(\mathrm{P}=0.065)$.

Of the patients, $70 \%(\mathrm{n}=703)$ were scalded, $16.8 \%$ were burned by flames, and $9.8 \%$ had electrical burns. Thirty-four (3.4\%) patients had both electrical shock and flame burns. The type of burn had no effect on mortality $(\mathrm{P}=0.057)$. 
Table 3. Characteristics of the Burn Site in the Died and Surviving Patient Groups

\begin{tabular}{|c|c|c|c|}
\hline & $\begin{array}{c}\text { Dead } \\
(n=78)\end{array}$ & $\begin{array}{c}\text { Living } \\
(\mathrm{n}=925)\end{array}$ & $\mathbf{P}$ \\
\hline & n (\%) & n (\%) & \\
\hline \multicolumn{4}{|l|}{ Burn site } \\
\hline Head & $23(29.5)$ & $219(23.7)$ & 0.057 \\
\hline Body & $32(41.0)$ & $378(40.9)$ & 0.620 \\
\hline Extremity & $58(74.4)$ & $728(78.7)$ & 0.058 \\
\hline Genitals & $2(2.6)$ & $24(2.6)$ & 0.660 \\
\hline \multicolumn{4}{|l|}{ Extent of burn } \\
\hline $1-9 \%$ & $44(56.4)$ & $526(56.9)$ & 0.075 \\
\hline $10-15 \%$ & $0(0.0)$ & $120(13.0)$ & 0.001 \\
\hline $16-20 \%$ & $2(2.6)$ & $109(11.8)$ & 0.021 \\
\hline $21-40 \%$ & $20(25.6)$ & $145(15.7)$ & 0.034 \\
\hline$>41 \%$ & $12(15.4)$ & $25(2.7)$ & 0.001 \\
\hline \multicolumn{4}{|l|}{ Burn degree } \\
\hline second degree (deep) & 74 (94.9) & $916(99.0)$ & 0.014 \\
\hline third degree & $10(12.8)$ & $114(12.3)$ & 0.065 \\
\hline
\end{tabular}

The incidence of delirium at the time of presentation $(23.1 \%)$ was significantly higher in the patients who died compared with the survivors $(10.4 \% ; \mathrm{P}=0.001)$. Moreover, the incidence of hyperuricemia at the time of presentation $(9 \%)$ was also significantly higher in the patients who died $(2.5 \% ; \mathrm{P}=0.006)$. The effect of other clinical and metabolic parameters on mortality was insignificant (Table 2).

The characteristics of the burn sites in the dead and surviving patients are shown in Table 3. The extremities and torso were the most common sites of burn injury. Although the most fatal progression was observed in the patients with extremity and torso burns, there was no significant difference between the groups in terms of burn site $(\mathrm{P}=0.063)$. The extent of the burn was $1-9 \%$ of the body surface in $56.8 \%(\mathrm{n}=570)$ of the patients. Burns covering $21-40 \%$ and $>41 \%$ of the body were significant predictors of mortality. The incidence of deep second-degree burns was higher among the survivors than among those who died $(99 \%$ vs. $94.9 \%$ ). No significant difference was found between the groups in terms of the presence of third-degree burns.

Early debridement was performed in $89.7 \%(n=70)$ of those who died and $50.3 \%(n=465)$ of the survivors. Skin grafting was performed in $23.1 \%(n=18)$ of those who died and $6.4 \%(\mathrm{n}=59)$ of the survivors. Fasciotomy was performed in $29.5 \%(\mathrm{n}=23)$ of those who died and $2.9 \%(\mathrm{n}=$
27) of the survivors. The rates of early debridement, grafting, and fasciotomy were higher in those who died than in survivors (all comparisons, $\mathrm{P}<0.001$ ).

The overall hospital stay was $18.72 \pm 1.84$ days in those who died versus $10.48 \pm 0.40$ days in the survivors; the difference was significant $(\mathrm{P}<0.001)$. The mean stay in the intensive care unit was $18.72 \pm 1.28$ days in those who died versus $0.40 \pm 1.86$ days in the survivors; the difference was significant $(\mathrm{P}=0.016)$.

\section{Discussion}

Burns are serious, complex injuries that frequently lead to disability and death. Consequently, their diagnosis and treatment requires a special approach. Knowledge of the underlying causes of mortality would facilitate research and programs to prevent burns. Advances in the treatment of burns in the last three to four decades have contributed to the decrease in mortality [5]. Various studies report burn-related mortality rates in burn clinics of $2.5-35 \%$ [6-9]. Mortality rates vary depending on the study population and the characteristics of the patients [6]. In the present study, the mortality rate was $7.7 \%$. Of the 297 patients admitted to the burn unit, $40(13.4 \%)$ died. 
Although various scoring systems have been reported for estimating the mortality risk of burned patients, there is no standard accepted system [10]. However, gender, age, burn surface area, presence of inhalation injury, co-morbid disease, co-existing trauma, and pneumonia have been reported to affect mortality $[11,12]$.

Advanced age is a risk factor for mortality; the reported mortality rate exceeds $30 \%$ in burned patients over the age of 60 years $[6,10]$. Advanced age is also a risk factor for late post-burn unfavorable outcomes [13]. Tung et al. [14] reported a male/female ratio of 1.94 for burn cases and found that this rate was lower in those under the age of 18 years. Han et al. [15] stated that $40 \%$ of burns occurred in those older than 65 years, $15 \%$ were among those under the age of 15 years, and burns among adults most commonly occurred between the ages of 30 and 40 years.

In our series, $62 \%$ of the 1003 burn patients were male, and $38 \%$ were female (Male/Female ratio 1.62 ). The mortality rate was significantly higher in males $(10.6 \%)$ than in females $(3.1 \%)$. Burns were prevalent between the ages 0 and 10 years, with the majority of these $(31 \%)$ in patients under the age of 2 years. Of the 311 cases in the 0 - 2-year age group, $14.1 \%$ showed fatal progression, whereas of the 157 cases in the 20 - 40-year age group, 14\% showed fatal progression. Of the 78 patients who died, 44 (56.4\%) were 0 - 2 years old, $22(28.2 \%)$ were 20 - 40 years old, and 12 $(15.4 \%)$ were $40+$ years old.

The most common types of burns are scald, flame, electrical, inhalation, and chemical burns. Nevertheless, the type of burn varies according to the country and region, and an association is likely between individual life style and the type of burn. Given the breakfast habits and tea culture in Turkey, the majority of burns in childhood are caused by tea and hot water spilled accidentally or result from inattention [16]. Tandoor burns are prevalent in the Eastern and Southeastern regions Turkey. Extensive and deep burns occur in women or small children who fall into a tandoor used to make bread [17]. A study conducted in Tehran showed that the majority of adult burns occur accidentally or due to petroleum products [18]. Illegal housing close to the high-voltage transmission lines and in technically inappropriate contributes to the incidence of electrical burns, which also occur frequently among poorly trained electrical workers [16]. Burns caused by touching electric lines while fitting and adjusting antennas on roofs are also common [19]. Kobayashi et al. [6] found flame burns in $46 \%$ of their series, scald burns in $32 \%$, and explosion-related burns in 7\%. Fukunishi et al. [20] reported that scald burns were common in small children, particularly in developed countries. In our series, most of the patients (70\%) had scald burns; the majorities were in the pediatric age group and were burned by boiling tea or water. Burns caused by boiling milk and hot meals were the second most common form of scald burns. There is a significant relationship between the incidence and mortality of burns and so- cioeconomic status (such as ethnicity, income level, family structure, education, career, and settlement) [21].

The location of a burn is important in terms of hospitalization and mortality. Burns on the hand, face, and perineum are important in terms of disability, but not mortality [15].

Han et al. [15] defined burns involving more than two regions as multiple burns and reported that such patients accounted for $74 \%$ of all burns. Isolated head and neck burns were observed in $6.1 \%$, whereas isolated upper extremity burns were observed in $9 \%$ and isolated lower extremity burns were observed in $8.6 \%$. In the present study, the extremities and torso were the most common sites of burn injuries. Although death was more prevalent among those with extremity and torso burns, there was no significant difference between the dead and surviving patient groups in terms of the location of the burn.

The percentage of the body surface burned and the depth of the burn are important prognostic factors. Treatment, follow-up, and mortality depend on both $[13,14]$. An extensive burn involving $>65 \%$ of the surface area is a major risk factor for mortality [14]. In the present study, the extent of the burn was between $1 \%$ and $9 \%$ in the majority $(56.8 \%)$ of patients. The percentage of patients with burns covering 1$9 \%$ of the surface area was $56.4 \%$ among patients who died and $56.9 \%$ among survivors; the difference was not significant. The proportion of those with burns covering $21-40 \%$ of the body surface was significantly higher in the patients who died (25.6\% vs. $15.7 \%)$, as was the proportion of patients with burns covering $>41 \%$ of the surface area $(15.4 \%$ vs. $2.7 \%$ ). The incidence of second-degree burns was significantly higher in the survivors (99\% vs. 94.9\%), whereas there was no significant difference between the groups in terms of the rate of third-degree burns. In our series, 9.8\% had electrical burns; although the number of third-degree burns among these patients was higher, the burn surface area was less than $10 \%$. This condition may contribute to the low mortality rate among patients with third-degree burns.

Tachycardia, tachypnea, hypotension, gradually increasing dyspnea, and decreased urine output are reported risk factors for mortality. Moreover, the presence of hyperthermia ( $>$ $\left.38^{\circ} \mathrm{C}\right)$, hypothermia $\left(<36{ }^{\circ} \mathrm{C}\right)$, hypocapnia $\left(\mathrm{Pa} \mathrm{CO}_{2}<32\right)$, leukocytosis (WBC $>12000 / \mu \mathrm{L})$, or $10 \%$ immature cells indicates that the patient is at serious risk of mortality $[8,18]$. In the present study, the presence of shock or tachypnea, late presentation, hyperglycemia, electrolyte imbalance, hypoalbuminemia, increased hepatic enzymes, increased CK-MB, increased troponin, increased CRP, leukocytosis, anemia, presence of metabolic acidosis, increased lactate levels, and an abnormal ECG had no effect on mortality. These measures may show that the mortality is not negatively affected with appropriate initial therapy. The rate of delirium at the time of presentation was significantly higher in the patients who died compared with the survivors $(23.1 \%$ vs. $10.4 \%)$. Furthermore, the rate of hyperuricemia at the time of pre- 
sentation was significantly higher in the patients who died (9.0\% vs. $2.5 \%)$.

Burn-related complications are generally seen in patients with impaired clinical and metabolic status and in those with late presentation to the hospital. Wound infection, shock, compartment syndrome, sepsis, acute renal failure, acute respiratory failure, and multi-organ failure might develop in such patients [22]. Shock is the most common cause of burn-related death in the early period, whereas multi-organ failure, SIRS, and sepsis are the most common causes subsequently [6]. In our series, the mortality rate was significantly higher in patients with sepsis, hypovolemic shock, and positive blood cultures $(88.3 \%, 97.0 \%$, and $73.5 \%$, respectively).

First-degree and superficial second-degree burns are usually treated without surgical intervention, with daily dressing changes, medications and albumin, blood products such as fresh frozen plasma and erythrocyte suspension, and a protein- and vitamin-enriched diet. Deep second- and thirddegree burns generally require surgical intervention, including escharotomy, debridement, skin grafts, and amputation [15]. In the present study, patients required 662 interventions including 535 early debridement, 77 grafting, and 50 fasciotomy. The number of operations per patient was 1.19 . The rates of early debridement, grafting, and fasciotomy were significantly higher in the patients who died.

In the present study, the length of the hospital stay in patients varied with the degree, percentage, and cause of burn. Burns treated in hospitals are usually severe, and flame burns require longer hospital stays than electrical and scald burns. Kobayashi et al. [6] reported that the risk factors for a longer hospital stay include flame burns, inhalation burns, and complications such as sepsis, shock, and multi-organ failure. Tung et al. [14] suggested that the hospital stay is shortened as the percentage area burned decreases $(<30 \%)$ and reported a mean hospital stay of 16.44 days. In our series, the mean hospital stay was $10.48 \pm 0.40$ days in the survivors and was significantly higher, $18.72 \pm 1.84$ days, in the patients who died.

\section{Conclusions}

The overall mortality rate was $7.7 \%$ in our series, which retrospectively evaluated the effect of scald, flame, and electrical burns on mortality. Extensive burns covering $>21 \%$ of the body surface conferred a high risk for mortality. Male gender, aged $>40$ years, a hospital stay longer than 10 days, delirium at the time of presentation, hyperuricemia, sepsis development, hypovolemic shock, and positive blood culture were significant predictors of mortality. Moreover, death was more common among the patients who required early debridement or underwent grafting and fasciotomy. We suggest that appropriate measures should be taken to avoid burns, as the primary prevention of burns is important. For this purpose, it is important to identify the regional causes of burns and the risk factors that influence mortality. When severe burns happen, however, the patients should be transferred to a burn unit as soon as possible.

\section{References}

1. Atiyeh BS, Costagliola M, Hayek SN. Burn prevention mechanisms and outcomes: pitfalls, failures and successes. Burns. 2009;35(2):181-193.

2. Sen S, Greenhalgh D, Palmieri T. Review of burn injury research for the year 2009. J Burn Care Res. 2010;31(6):836-848.

3. Evers LH, Bhavsar D, Mailander P. The biology of burn injury. Exp Dermatol. 2010;19(9):777-783.

4. Osborn K. Nursing burn injuries. Nurs Manage. 2003;34(5):49-56.

5. Bloemsma GC, Dokter J, Boxma H, Oen IM. Mortality and causes of death in a burn centre. Burns. 2008;34(8):1103-1107.

6. Kobayashi K, Ikeda H, Higuchi R, Nozaki M, Yamamoto Y, Urabe M, Shimazaki S, et al. Epidemiological and outcome characteristics of major burns in Tokyo. Burns. 2005;31 Suppl 1:S3-S11.

7. Fadeyibi IO, Mustapha IA, Ibrahim NA, Faduyile FI, Faboya MO, Jewo PI, Ademiluyi SA. Characteristics of paediatric burns seen at a tertiary centre in a low income country: a five year (2004-2008) study. Burns. 2011;37(3):528-534.

8. Al B, Yildirim C, Coban S, Aldemir M, Guloglu C. [Mortality factors in flame and scalds burns: our experience in 816 patients]. Ulus Travma Acil Cerrahi Derg. 2009;15(6):599-606.

9. Coban YK, Erkilic A, Analay H. Our 18-month experience at a new burn center in Gaziantep, Turkey. Ulus Travma Acil Cerrahi Derg. 2010;16(4):353-356.

10. Wibbenmeyer LA, Amelon MJ, Morgan LJ, Robinson BK, Chang PX, Lewis R, 2nd, Kealey GP. Predicting survival in an elderly burn patient population. Burns. 2001;27(6):583-590.

11. Smith DL, Cairns BA, Ramadan F, Dalston JS, Fakhry SM, Rutledge R, Meyer AA, et al. Effect of inhalation injury, burn size, and age on mortality: a study of 1447 consecutive burn patients. J Trauma. 1994;37(4):655659.

12. McGwin G, Jr., George RL, Cross JM, Rue LW. Improving the ability to predict mortality among burn patients. Burns. 2008;34(3):320-327.

13. Klein MB, Lezotte DC, Heltshe S, Fauerbach J, Holavanahalli RK, Rivara FP, Pham T, et al. Functional and psychosocial outcomes of older adults after burn injury: results from a multicenter database of severe burn injury. J Burn Care Res. 2011;32(1):66-78.

14. Tung KY, Chen ML, Wang HJ, Chen GS, Peck M, Yang 
J, Liu CC. A seven-year epidemiology study of 12,381 admitted burn patients in Taiwan--using the Internet registration system of the Childhood Burn Foundation. Burns. 2005;31 Suppl 1:S12-17.

15. Han TH, Kim JH, Yang MS, Han KW, Han SH, Jung JA, Lee JW, et al. A retrospective analysis of 19,157 burns patients: 18-year experience from Hallym Burn Center in Seoul, Korea. Burns. 2005;31(4):465-470.

16. Turegun M, Sengezer M, Selmanpakoglu N, Celikoz B, Nisanci M. The last 10 years in a burn centre in Ankara, Turkey: an analysis of 5264 cases. Burns. 1997;23(78):584-590.

17. Al B, Coban S, Guloglu C. Tandir burns in and around Diyarbakir, Turkey. Ulus Travma Acil Cerrahi Derg. 2010;16(1):59-62.

18. Zarei MR, Dianat S, Eslami V, Harirchi I, Boddouhi N, Zandieh A, Rasouli MR. Factors associated with mortality in adult hospitalized burn patients in Tehran. Ulus
Travma Acil Cerrahi Derg. 2011;17(1):61-65.

19. Celikoz B, Sengezer M, Selmanpakoglu N. Four limb amputations due to electrical burn caused by TV antenna contact with overhead electric cables. Burns. 1997;23(1):81-84.

20. Fukunishi K, Takahashi H, Kitagishi H, Matsushima T, Kanai T, Ohsawa H, Sakata I. Epidemiology of childhood burns in the critical care medical center of Kinki University Hospital in Osaka, Japan. Burns. 2000;26(5):465469.

21. Park JO, Shin SD, Kim J, Song KJ, Peck MD. Association between socioeconomic status and burn injury severity. Burns. 2009;35(4):482-490.

22. Shupp JW, Pavlovich AR, Jeng JC, Pezzullo JC, Oetgen WJ, Jaskille AD, Jordan MH, et al. Epidemiology of bloodstream infections in burn-injured patients: a review of the national burn repository. J Burn Care Res. 2010;31(4):521-528. 